\title{
Swiss 'dignity' law is threat to plant biology
}

When it comes to the ethics of experimenting on living subjects, plant biologists have had cause for a certain smugness. But perhaps no longer in Switzerland.

The Swiss federal government's ethics committee on non-human biotechnology has mapped out guidelines to help granting agencies decide which research applications deeply offend the dignity of plants - and hence become unfundable.

Although most people might be bewildered that a discussion on how to define 'plant dignity' should be taking place at all, the stakes for Swiss plant scientists are high. The Gene Technology Law, which came into effect in 2004, stipulates that 'the dignity of creatures' should be considered in any research. The phrase has been widely criticized for its general woolliness, but it indisputably includes plants.

All plant biotechnology grant applications must now include a paragraph explaining the extent to which plant dignity is considered. "But scientists don't know what it means," says Beat Keller of the Institute of Plant Biology at the University of Zurich who is running the first field trial - of disease-resistant corn (maize) - to be approved under the new legislation.

"At the moment not even authorities who decide on grants know what the 'dignity of plants' really means," says Markus Schefer, a constitution lawyer at the University of Basel and a member of the ethics committee. "That's why we were asked to deliberate."

The constitution says that the 'dignity of creatures' must be taken into account in the gene-technology arena, which is why the term has been adopted into the regulations.

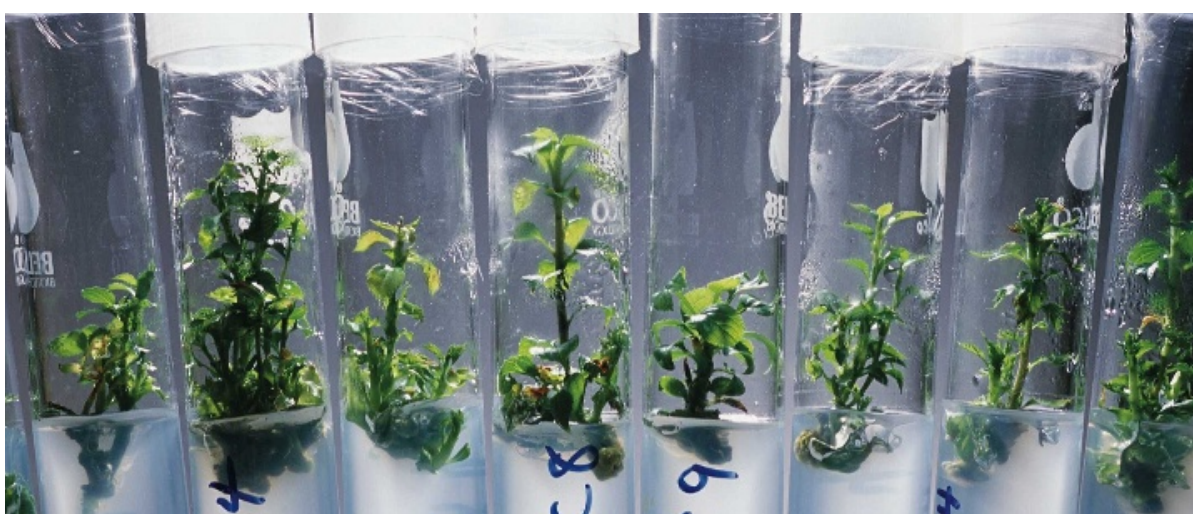

Living creatures trapped in undignified conditions? A tricky ethical question for Swiss plant biologists.

The government called on the advice of its ethics committee two years ago to help develop a definition for plants. "My first reaction was - what the heck are we doing considering the dignity of plants," says Schefer. "But this very broad provision exists, and we have to help to prevent a legal mire."

The committee has created a decision tree presenting the different issues that need to be taken into account for each case. But it has come up with few concrete examples of what type of experiment might be considered an unacceptable insult to plant dignity. The committee does not consider that genetic engineering of plants automatically falls into this category, but its majority view holds that it would if the genetic modification caused plants to 'lose their independence' - for example by interfering with their capacity to reproduce. The statement has confused plant geneticists, who point out the contrast with traditional plant-hybridization technologies, for example in roses, which require male sterility, and the commercial development of seedless fruits.

Keller sees the issue as providing another tool for opponents to argue against any form of plant biotechnology, which is already very difficult to conduct in Switzerland. Schefer says that things will start to become clearer when legal challenges to specific research projects come to court, and case law becomes established.

The definition of what constitutes dignity in animals is currently being tested in a Zurich court. Primate-research projects at the ETH Zurich technology institute, which involve separating young marmosets from their mothers, have been put on hold while the court decides if they conflict with the animals' dignity. A ruling is expected this year. Whichever way it falls, the decision is likely to end up in the federal constitutional court.

Alison Abbott every June and a decrease during December. The seasonal oscillation, they claimed, was due to Earth's annual motion with and against a stream of dark matter swirling around the Milky Way.

But rival groups failed to see the signal and heaped criticism on the group. They demanded proof that the Italians' detection was not caused by systematic errors such as natural radiation or glitches in their electronics.

This time around, the DAMA/LIBRA team seems to have addressed some of those concerns, according to Bernard Sadoulet, an astrophysicist at the University of California, Berkeley. For example, their new detector uses larger, less strongly radioactive crystals, and they have proven the stability of their detectors.
But once again, DAMA/LIBRA's rivals are coming up empty-handed. Sadoulet's own Cryogenic Dark Matter Search II detector announced a null result earlier this year (see Nature 452, 6-7; 2008). And other second- and third-generation experiments are similarly failing to see a signal. If the signal DARMA gets is dark matter, Sadoulet says, "it's certainly not the dark matter we were looking for". He also continues to criticize the group for failing to share enough details of its data. "There has not been enough information provided to the community," he says.

Bernabei defends her group's finding. Most other detectors try to measure direct collisions between a dark-matter particle and an atomic nucleus, she says. DAMA/LIBRA is the only experiment with the years of data needed to see the annual fluctuation in dark-matter particles. And the fluctuation matches "all the several requirements of dark matter", she says, adding that two papers have just been posted on the popular preprint server ArXiv, which provide the details of her work.

But unless another team sees something, Gerbier says, it's unlikely that the wider physics community will accept the Italian claim. "There should be different ways of seeing the same thing," he says. "A single experiment cannot discover dark matter."

Bernabei agrees. Proving her team's findings will take "time and patience", she says. Geoff Brumfiel 